\title{
Penerapan Dapur Sehat dan Penggunaan Laru Alami untuk Meningkatkan Kualitas Gula Kelapa
}

\author{
Tarjoko $^{1 *}$, Suyono $^{1}$, Yulia $^{1}$ dan Lilia Nawang Anjasari ${ }^{1}$ \\ ${ }^{1}$ Fakultas Pertanian, Universitas Jendral Soedirman, Purwokerto 53132 \\ *Email: tarjokoarca.ms@,gmail.com
}

\begin{abstract}
Abstrak
Desa rangkah merupakan salah satu sentra penghasil gula di Kabupaten Kebumen. Terdapat sekitar 51unit industri gula kelapa dalam skala rumah tangga. Gula kelapa masih diproduksi secara tradisional, menggunakan dapur yang kurang bersih dan laru sintetis ("Sodium metabisulfida") yang turut andil dalam menghasilkan gula yang tidak sehat. Salah satu program kegiatan yang dilaksanakan adalah pembenahan dapur dan penggunakaan laru alami untuk memperbaiki kualitas gula kelapa menjadi lebih sehat. Kegiatan KKN dapat meningkatkan kualitas dapur sehat sebesar 33,60\% dan dengan gula menggunakan laru alami menampilkan warna, tekstur, rasa dan flavor yang lebih disukai daripada gula dengan menggunakan laru sintetis "Sodium metabisulfida".
\end{abstract}

Kata kunci: Dapur sehat, laru alami, Gula kelapa

\begin{abstract}
Rangkah Village is one of the sugar producing centers in Kebumen Regency. There are about 51 units of coconut sugar industry in household scale. Coconut sugar is still produced traditionally, using a kitchen that is less clean and synthetic chemistry ("Sodium metabisulfida") that contribute to the production of unhealthy sugar. One of the program activities implemented is the kitchen and the utilization of natural preservation to improve the coconut sugar becomes healthier. KKN activities can improve the quality of healthy kitchen by $33.60 \%$ and with sugar using natural laru displaying the preferred color, texture, flavor and flavor of sugar by using the synthetic "Sodium metabisulfide".
\end{abstract}

Keywords: Healthy Kitchen, natural preservation, Coconut Sugar.

Format Sitasi: Tarjoko, Suyono \& Anjasari L. (2019). Penerapan Dapur Sehat dan Penggunaan Laru Alami untuk Meningkatkan Kualitas Gula Kelapa. Jurnal Solma, 08(1), 39-46. Doi: http://dx.doi.org/10.29405/solma.v8i1.2967.

Diterima: 28 Januari 2019 | Revisi: 16 April 2019 | Dipublikasikan: 30 April 2019.

\section{PENDAHULUAN}

Desa Rangkah merupakan salah satu sentra penghasil gula kelapa di Kecamatan Buayan, Kabupaten kebumen. Gula kelapa cairan ("nira") yang dikeluarkan oleh bagian pangkal (tandan) bunga tanaman "mayang" pada saat di sadap/deres (dipangkas). Pada proses pengambilannya, cairan nira tersebut ditampung dalam wadah "pongkor" dan dibutuhkan waktu selama 12 jam untuk mendapatkan volume nira yang cukup dalam pembuatan gula kelapa. Permasalah krusial yang dihadapi selama penampungan nira dalam 
pongkor adalah kerusakan nira akibat terjadinya fermentasi oleh mikroba kotaminan. Menurut (Suhardiyono, 1991)nira sangat mudah mengalami fermentasi karena mengadung ragi yang sangat aktif, sehingga mudah sekali rusak. Bahkan begitu keluar dari penyadapan, ragi langsung bekerja dan fermentasi dan dalam waktu satu hari nira akan habis dikonversi, sehingga berasa asam, warna menjadi keruh dan kenuning-kuningan. Lebih lanjut (Muhtadi, T.R., 1992) mengatakan bahwa aktifitas khamir "saccharomyces cereviciae, lactobacillus, acetobacter, stertococcus, merupakan mikroba yang terlibat dalam fermentasi nira menghasilkan alkohol dan asam. Gula yang telah mengalami fermentasi akan mudah rusak dan bahkan tidak dapat dicetak karena gula tidak dapat mengeras dan memadat. Upaya pencegahan kerusakan akibat mikrobia yang dilakukan oleh para perajin gula di Desa Rangkah menggunakan bahan pengawet sulfit (Nametabisulfit) yang disebut obat gula, dalam bentuk garam sulfit. Penggunaan obat gula semakin marak dikarenakan bahan tersebut effektif sebagai antimikrobia, mudah didapat dipasar, harganya terjangkau dan masih kurang pemahamannya dan kesadaran perajin akan bahaya sulfit. sulfit digunakan sebagai pengawet karena molekul bereaksi dengan asetaldehid mebentuk senyawa yang tidak dapat difermentasi oleh enzim mikroba, selain hasil reaksinya mengikat melanoidin, sehingga mencegah timbulnya warna cokelat. Hanya saja penggunaan sulfit sangat berbahaya bagi kesehatan terutama bagi penderita penyakit asma dan bisa menstimulir terjadinnya kanker (karsinogenik).

Terdapat 51 perajin di Desa Rangkah yang mengolahnya gula kelapa di ruang pengolahan (dapur) yang sangat sederhana Kondisi dapur seperti tersebut menyebabkan adanya keluhan sesak nafas setelah selesai memasak. Hal tersebut di atas perlu dibenahi agar memenuhi persayatan cara produki yang baik (CPB) atau Good manufacturing Pratice (GMP) dengan menerapkan dapur sehat. Lebih lanjut menurut (Astuti, 2002) GMP bukan hanya merupakan tuntutan konsumen lokal, tetapi merupakan tuntutan kosumen Global.

\section{MASALAH}

Na-metabisulfit sebagai pengawet dapat terakumulasi di dalam tubuh, yang akan menimbulkan permsalahan kesehatan dikemudian hari. Bagi orang yang peka sulfit menyebab-kan sesak dada, sesak nafas, gatal-gatal, bengkak dan lebih jauh lagi dapat mengakibatkan kematian, pernah terjadi orang meninggal dunia akibat serangan mendadak anaphylactic setelah menyantap makan yang diawetkan menggunakan sulfit (Nurjanah, 2004)Salah satu cara menggantikannya adalah menggunakan bahan-bahan alami makanan, seperti pengawet, pewarna, flavor, dan aditif lainnya (Suliantari, 2009) 
Keberadaan dapur yang dimiliki perajin gula masih sangat sederhana,karena pembuatan gula kelapa dianggap sebagai pekerjaan sambilan. Dapur di banyak perajin mempunyai multifungsi selain sebagai tempat pengolah gula juga sebagai penyimpan kayu kakar dan tempat penyimpan produk pertanian di atas dapur (para-para). Asap yang bercampur dengan abu dan kotoran hasil pembakaran, (KHP) yang semakin lama semakin banyak. KHP ini terbawa sirkulasi asap di dapur pengolahan yang dapat mengurangi kebersihan gula kelapa. Wajan, ayakan, solet sebagai alat pengolah gula juga tergeletak disembarang tempat yang mengurangi kebersihannya. Tungku yang digunakan dalam penglohan gula masih tradisional. Tungku disamping boros bahan bakar, juga dapat mengeluarkan kepulan asap yang mengakibatan ruangan dapur menjadi semakin kotor, akibat dari kepulan asap yang tebal. Kondisi dapur seperti tersebut menyebabkan adanya keluhan sesak nafas setelah selesai memasak.

\section{METODE PELAKSANAAN}

Metode yang digunakan dalam kegiatan KKN PPM ini adalah pelatihan, demplot dan pendampingan. Sebelum dilakukan pelatihan terlebih dahulu dilakukan sosialisai dengan sistem "endong". Pendekatan masyarakat yang digunakan adalah PRA (Partisipatory Rural Appraisal), dengan tujuan utama, yaitu: (1) tujuan praktis, yaitu menyelenggarakan kegiatan bersama masyarakat untuk mengupayakan pemenuhan kebutuhan praktis dan peningkatan kesejahteraan masyarakat dan sekaligus sebagai sarana proses belajar, (2) tujuan strategis, yaitu membawa visi untuk mencapai pemberdayaan masyarakat dan perubahan sosial melalui pengembangan masyarakat dengan menggunakan pendekatan pembelajaran. Tingkatan partisipasi masyarakat ini akan tercapai apabila pengorganisasian masyarakat mengarah ke tahapan pembebasan diri sampai kepada tingkat partisipasi mandiri (self mobilization). Dengan cara ini para perajin gula kelapa dapat secara langsung berdiskusi dan melihat hasil demplot/contoh.

Evaluasi terhadap penerapan dapur sehat adalah melalui penilaian penerapan dapur sehat, higienitas, dan K3 dengan cara mencheklist poin dari beberapa kreteria dapur sehat menurut BPOM. Penilaian ini dilakukan sebelum dan setelah renovasi dapur untuk mengetahui peningkatan kualitas dapur yang mendukung proses produksi gula kelapa organik. (BPOM, 2002) menetapkan sejumlah persyaratan yang harus dipenuhi terkait dengan CPB, yaitu: 1). Lokasi dan lingkungan produksi, 2). Bangunan dan fasilitas, 3). Peralat produksi, 4). Suplai air atau sarana penyediaan air, 5). Kesehatan karyawan, 6). Pemeliharaan dan program hygiene, 7). Sanitasi, 8). Penyimpanan, 9). Pengendalian 
Proses, 10). Pelabelan pangan, 11). Pengawasan dan penanggung jawab, 12). Penarikan produk, 13). Pencatatan dan dokumentasi, 14). Pelatihan karyawan.

Evaluasi penggunaan laru dilakukan dua uji organoleptik yang dilakukan secara bersamaan. Laru yang digunakan adalah "Tangkis" yang terbuat dari bahan kapur, dan tatal nangka. Panelis yang digunakan dalam uji organoleptik sebanyak 15 orang dan merupakan panelis semi terlatih. Sampel yang digunakan adalah gula nira kelapa organik dan gula nira kelapa dengan laru sulfit masing - masing berasal dari tiga kelompok. Adapun uji yang diterapkannya yaitu Uji Hedonik dan Uji Skoring.

Uji hedonik merupakan uji yang digunakan untuk mengetahui kesan kesukaan pada suatu produk. Uji hedonik dilakukan dengan mengukur tingkat kesukaan panelis terhadap sampel yang telah diberikan. Tingkat-tingkat kesukaan ini disebut sebagai skala hedonik, misalnya amat sangat suka, sangat suka, suka, agak suka, netral, agak tidak suka, tidak suka, sangat tidak suka dan amat sangat tidak suka.

Uji skoring adalah salah satu uji skalar pada pengujian organoleptik. Penilaian diberikan pada setiap parameter yang telah ditunjukan untuk sampel yang telah disediakan. Menurut (Setyaningsih, D, Apriyantono, A, dan Sari, 2010) uji skoring dapat diterapkan untuk mengukur dan membandingkan produk-produk sejenis dengan memberikan penilaian atau skor. Dalam hal ini yang dibandingkan adalah gula nira organik dengan gula nira yang memakai laru sulfit.

\section{HASIL DAN PEMBAHASAN}

\section{Dapur sehat, Higienitas dan K3}

Penilaian penerapan dapur sehat, higienitas dan K3 di Desa Rangkah dilakukan dengan cara mencheklist poin dari beberapa kriteria dapur sehat menurut BPOM. Penilaian ini dilakukan sebelum dan setelah renovasi dapur untuk mengetahui peningkatan kualitas dapur yang mendukung proses produksi gula kelapa organik. Kegiatan penilaianya di terapkan pada lokasi demplot dan pendampingan. Lokasi yang dijadikan demplot adalah dapur milik Pak Kasid, Pak Salijan, dan pak Lasikun. Sedangkan lokasi yang dijadikan kegiatan pendampingan dapur milik Pak Kasimun, Pak Purwito, Parmin. (Tabel 1).

Tabel 1. Poin dapur sebelum dan sesudah renovasi

\begin{tabular}{llrr}
\hline Kegiatan & Lokasi kegiatan & $\begin{array}{l}\text { sebelum } \\
\text { renovasi } \\
\text { (point) }\end{array}$ & $\begin{array}{l}\text { Setelah } \\
\text { renovasi } \\
\text { (point) }\end{array}$ \\
\hline DEMPLOT & Kasid di Dusun pengada & 22,00 & 40,00 \\
& Salijan di Dusun serang & 29,00 & 34,00 \\
& & Email: $\underline{\text { solma@ } \text {,uhamka.ac.id } \mid 42}$
\end{tabular}




\begin{tabular}{llll} 
& Lasikun di Dusun juru & & \\
& Tengah & 15,00 & 25,00 \\
& Kasimun di dusun Pengada & 14,00 & 22,00 \\
& Purwito di Dusun juru & & \\
& tengah & 18,00 & 27,00 \\
Pendampingan & Parmindi Dusun Serang & 25,00 & 33,00 \\
& Nartodi Dusun Juru Tengah & 15,00 & 55,00 \\
& Sapondi Dusun Juru Tengah & 14,00 & 24,00 \\
& Parto Di Dusun juru Tengah & 15,00 & 25,00 \\
\hline
\end{tabular}

Berdasarkan tersebut di atas, peningkatan poin setelah dapur direnovasi sesuai kriteria dapur sehat menurut standar BPOM. Dari poin tersebut dapat dihitung prosentasenya dengan rumus:

$$
\% \text { hasil }=\frac{\text { jumlah poin }}{\text { total dapur sehat }} \times 2,5
$$

Dengan menggunakan rumus tersebut didapatkan hasil nilai dapur sebelum renovasi sebesar $46,67 \%$ dan dapur setelah renovasi sebesar 70,27\%. Peningkatan ini menunjukkan hasil yang baik karena dapat menjadi indikator meningkatnya kesadaran perajin gula kelapa akan pentingnya penerapan CPB untuk meningkatkan kualitas produksi gula kelapa.

Peningkatan nilai dapur setelah renovasi tidak dapat mencapai $100 \%$ dikarenakan beberapa hal diantaranya keterbatasan biaya serta keterbatasan fasilitas untuk memenuhi semua kriteria dapur sehat menurut BPOM.

\section{Laru alami}

Hasil penerapan laru dilakukan uji organoleptik dengan menggunakan panelis semi terlatih. Parameter yang diujikan meliputi warna, tekstur, rasa, flavor dan kesukaaan. Paramter tersebut diujikan dengan menggunakan metode uji skoring dan uji hedonik. Hasil pengujian gula cetak pada berbagai perlakuan menggunakan tankis dan sulfide disajikan pada Gambar 1. 


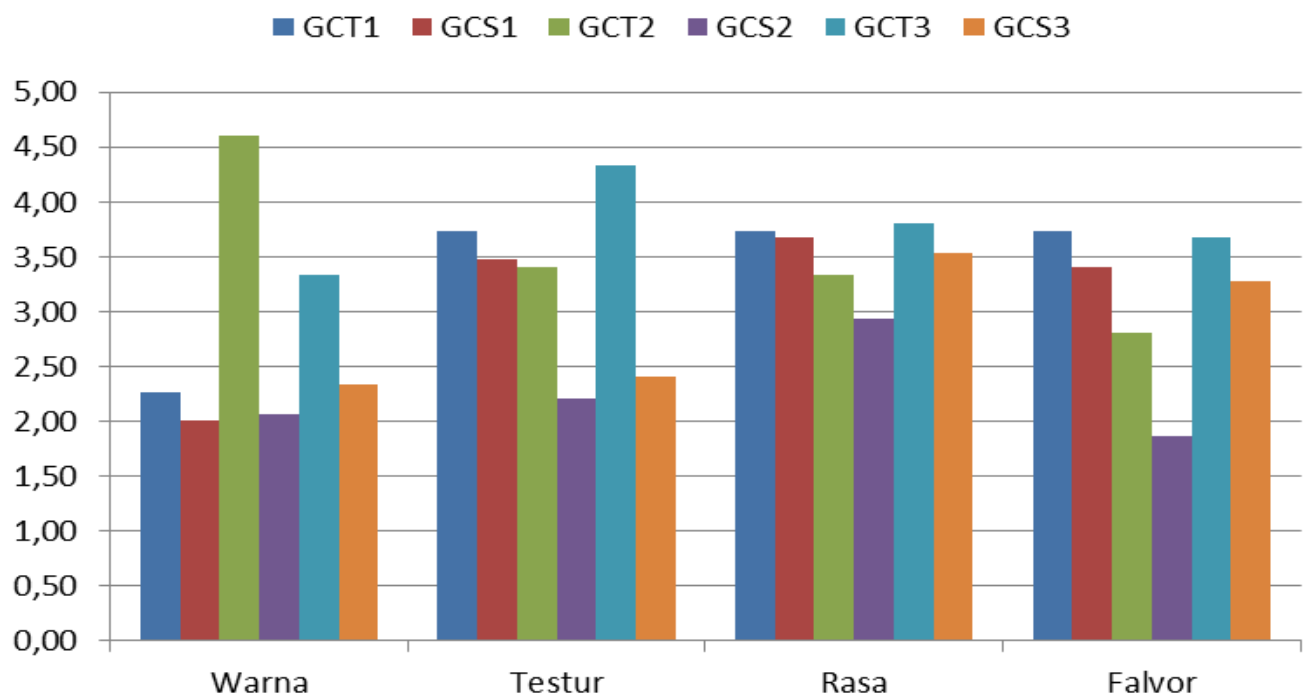

Gambar 1. Hasil skoring uji organoleptik perlakuan laru alami (tangkis) dan sulfide Ket: GCT: Gula Cetak Tangkis; GCS: Gula Cetak Sulfid.

\section{a. Warna Gula}

Hasil uji skoring parameter warna saat di rata - rata menunjukan bahwa adanya perbedaan warna gula nira laru organik dengan gula nira laru sulfit. Warna yang dimiliki oleh gula laru organik lebih coklat dibandingkan dengan gula nira laru organik. Sesuai dengan SNI Gula cetak, warna gula nira yang masih memasuki standar adalah warna kuning kecoklatan hingga coklat tua. Produk dengan Gula cetak tangkis 3 dan Gula cetak tangkis 2 memiliki perbedaan dibandingkan dengan gula sulfit. Sehingga dapat disimpulkan adanya perbedaan antara gula cetak laru organik dengan gula cetak laru sulfit. Perbedaan ini dapat dijadikan sebagai suatu perbandingan bahwa penggunaan laru organik pada pembuatan gula nira lebih baik karena standar warna yang didapatkan hampir sama dengan standar warna SNI.

\section{b. Tekstur}

Hasil parameter tekstur gula nira menunjukan adanya perbedaan pada tekstur. Hal ini dikarenakan penggunaan laru sulfit akaan menyebabkan penurunan tingkat kekerasan apabila disimpan lama. Parameter tekstur dapat dijadikan salah satu cara pengrajin gula nira untuk menentukan standar mutu gula nira.

\section{c. Rasa}

Rasa berkaitan dengan indera pencicip. Parameter ini memiliki andil yang cukup besar dalam pengecekan mutu. Gula cetak laru tangkis memiliki nilai rata - rata yang lebih 
tinggi jika dibandingkan dengan gula nira laru sulfit. Penggunaan laru mempengaruhi rasa pada gula nira yang dihasilkan. Jika menggunakan laru sulfit akan menghasilkan rasa yang tidak enak di tenggorokan dan lidah. Penggunaan sulfit pada saat mengawetkan nira yang dideres tidak menggunakan takaran yang pas sehingga sulfit mempengaruhi rasa saat diolah menjadi gula nira. Selain itu penggunaan laru sulfit juga kurang baik karena salah satu parameter lainnya adalah laru tersebut tidak dapat mengolah nira menjadi gula Kristal.

\section{d. Flavor}

Flavor merupakan parameter yang melibatkan parameter lainnya meliputi rasa, aroma dan mouthfeel setelah mencicipi sampel. Berdasarkan hasil rata - rata flavor yang didapatkan dari uji panelis menyimpulkan bahwa flavor gula laru tangkis lebih enak dibanding dengan gula laru sulfit. Flavor pada gula nira yang enak merupakan pada gula cetak tangkis 1 . Hal ini menandakan bahwa penggunaan laru organik memiliki rasa yang enak dan mudah diterima. Flavor yang enak akan menguntukn pengrajin gula nira saat memproduksi gula nira.

\section{e. Kesukaan}

Kesukaan merupakan parameter dari uji hedonik. Kesan yang diberikan panelis dapat menjadi suatu acuan untuk dijadikan sebagai standar. Banyak faktor yang dapat mempengaruhi kesukan. Mengetahui kesukaan konsumen dapat menjadikan suatu proses sebagai standar dan dapat ditingkatkan lagi cara yang digunakan untuk mengolah. Hasil rata - rata tertinggi yang didapatkan dari uji hedonik yaitu gula cetak tangkis 1 . Hal ini menandakan bahwa panelis menyukai produk organik. Hasil rata - rata dapat dilihat dari tabel diatas ini.

\section{KESIMPULAN}

Penerapan dapur sehat pada kegiatan KKN dapat meningkatkan kualitas dapur sehat sebesar 33,60\% dan dengan gula menggunakan laru alami menampilkan warna, tekstur, rasa dan flavor yang lebih disukai daripada gula dengan menggunakan laru sintetis "Sodium metabisulfida".

Supaya gula menjadi lebih sehat maka untuk mencegah kerusakan akibat fermentasi sebelum diolah dapat digukana laru alami "Tangkis. Demikian juga agar perajin gula lebih sehat dan hasil olahan gulanya menjadi lebih hygien perlu menerapkan CPB sesuai aturan (BPOM, 2002) 


\section{UCAPAN TERIMA KASIH}

Ucapan terima kasih kami ucapan kepada Direktotat Penelitian dan Pengabian Kepada Masyarakat, Kementrian Riset DIKTI yang telah mendanai sehingga kegiatan KKN PPM dan Desa Rangkah yang turut andil dalam mensukseskan kegiatan ini.

\section{DAFTAR PUSTAKA}

Astuti, S. (2002). Tinjauan Aspek Mutu dalam Kegiatan Industri Pangan. Institut Pertanian Bogor.

BPOM. (2002). Cara Produksi Pangan yang Baik untuk Industri Rumah Tangga. Retrieved August 20, 2017, from http://www.ebookpangan.com/EBOOK\%2520GRATIS/Ebook\%2520Pangan/PRODU KSI\%2520PANGAN\%2520YANG\%2520BAIK\%2520SKALA\%2520RT\%25 20DAN\%2520PEDOMAN\%25 20PE-NILAIAN.pdf.

Muhtadi, T.R., dan S. (1992). Ilmu Pengetahuan Bahan Pangan. Departemen Pedididikan dan Kebudayaan. Direktorat Jenderal Tinggi, Pusat Aantar Universitas Pangan dan Gizi. Institut Pertanian Bogor.

Nurjanah, N. (2004). Diversifikasi Penggunaan Cengkeh. Balai Besar Penelitian dan Pengembangan Pasca Panen Pertanian. bogor.

Setyaningsih, D, Apriyantono, A, dan Sari, M. (2010). Analisa Sensori Industri Pangan dan Agro. bogor: IPB Press.

Suhardiyono. (1991). Tanaman krlapa, budidaya dan pemanfaatannya. yogyakarta: kanisius.

Suliantari. (2009). Aktivitas antibakteri dan mekanisme penghambatan Ekstrak Sirih Hijau(piper Betle Linn) Terhadap bakteri Patogen Pangan (On line). Sekolah Pasca Sarjana Institut Pertanian Bogor.

\section{(c) (i)}

(C) 2019 Oleh authors. Lisensi Jurnal Solma, LPPM-Uhamka, Jakarta. Artikel ini bersifat open access yang didistribusikan di bawah syarat dan ketentuan Creative Commons Attribution (CC BY) license. (http://creativecommons.org/licenses/by/4.0/). 